\title{
A gapA PCR-sequencing Assay for Identifying the Dickeya and Pectobacterium Potato Pathogens
}

Jérémy Cigna, Seed Innovation Protection Research Environment, Comité Nord-SIPRE, 62217 Achicourt, France; and Institute for Integrative Biology of the Cell, CNRS CEA Univ. Paris-Sud, Université Paris-Saclay, 91198 Gif-sur-Yvette, France; Pauline Dewaegeneire, Amélie Beury, and Virginie Gobert, Seed Innovation Protection Research Environment, Comité Nord-SIPRE, 62217 Achicourt, France; and Denis Faure, Institute for Integrative Biology of the Cell, CNRS CEA Univ. Paris-Sud, Université Paris-Saclay, 91198 Gif-sur-Yvette, France

\begin{abstract}
Several pectinolytic Pectobacterium and Dickeya species and subspecies are causative agents of blackleg and soft rot diseases on potato plants and tubers. Rapid and accurate identification of these taxa is a crucial issue for the production and international trade of potato seed-tubers. Here, we developed a PCR-sequencing tool to easily characterize the different Pectobacterium and Dickeya taxa. The gapA gene sequences from 53 published genomes were aligned and a phylogeny tree was constructed. A set of 35 signature nucleotides was

discovered to distinguish the Pectobacterium and Dickeya genera, species, and subspecies. Then, a PCR-primer couple was designed for amplifying the gapA gene in pectinolytic enterobacteria. The primers were tested on 22 isolates recovered from blackleg symptoms in several potato fields. Amplicons were sequenced and signaturenucleotides were analyzed. A phylogeny that includes gapA sequence specimens confirmed the taxonomical identification of these environmental isolates.
\end{abstract}

Dickeya and Pectobacterium are pectinolytic enterobacteria inducing damage on a wide range of plants (Ma et al. 2007; Samson et al. 2005; Waldee 1942). These pathogens produce extracellular plant cell-wall-degrading enzymes that cause blackleg and soft rot diseases (Barras et al. 1994). These diseases are a major problem for potato farmers. The disease dynamics are complex, as is the identification of the causative agent because several Pectobacterium and Dickeya species provoke similar symptoms on potato plants (Pérombelon 2002). In potato fields, the taxa isolated from symptomatic tissues are: D. dianthicola (Ddi); D. solani (Dsol), which recently emerged; and D. dadantii (Ddad); and P. atrosepticum $(\mathrm{Pa})$; $P$. parmentieri $(\mathrm{Pp})$, which results from the split of $P$. wasabiae $(\mathrm{Pw}) ;$ P. carotovorum subsp. carotovorum $(\mathrm{Pcc})$; and $P$. carotovorum subsp. brasiliense (Pcb) (de Werra et al. 2015; Duarte et al. 2004; Gardan et al. 2003; Khayi et al. 2016; Samson et al. 2005; Toth et al. 2011). Remarkably, some Pectobacterium and Dickeya species isolated from nonpotato host plants cultivated in the same area should be considered as potential potato pathogens. As an example, $P$. carotovorum subsp. odoriferum (Pco), usually isolated from chicory, is able to induce soft rot symptoms when inoculated onto potato tubers (Waleron et al. 2014).

To limit the propagation of the pathogens, identification of blackleg fields and sorting of tuber-seed lots are regulated in several countries (Czajkowski et al. 2011). For 20 years, several PCR-based methods have been developed for detecting and identifying Dickeya and Pectobacterium pectinolytic enterobacteria. Among the first sets of PCR-primers designed and still used today, Y1-Y2 (Darrasse et al.

Corresponding author: Denis Faure; E-mail: denis.faure@i2bc.paris-saclay.fr

gapA sequences from strains isolated in potato field appear in the GenBank nucleotide sequence databases with the accessions number KY047578 to KY047599.

This work benefited from a French State grant (reference ANR-10-LABX0040-SPS) managed by the French National Research Agency under an Investments for the Future program (reference no. ANR-11-IDEX-0003-02). This work is also supported by the CNRS (I2BC-SB2016), Comite NordSIPRE, and ANR COMBICONTROL (ANR-15-CE21-0003).

Accepted for publication 16 March 2017.

() 2017 The American Phytopathological Society
1994) and ADE1-ADE2 (Nassar et al. 1996) target Pectobacterium and Dickeya species, respectively. Some other PCR-primers are species-specific, targeting P. atrosepticum (Frechon et al. 1998), Pcb (Duarte et al. 2004), and P. wasabiae (Kim et al. 2012). Many other PCR-primer sets and methods are all available for the detection of pectinolytic bacteria. These include PCR-RFLP (Hélias et al. 1998), multiplex PCR (Potrykus et al. 2014), and real-time PCR (Laurila et al. 2010). These methods can be applied directly on environmental DNA and are therefore suitable for detecting pathogens in a complex matrix. Although rapid and easy to run, these taxonspecific PCR methods require one-by-one PCR-amplifications in numbers that are at least equal to-and often greater than-that of the searched taxon. To circumvent this constraint in the course of taxonomical characterization of pure isolates, some PCR-sequencing barcodes were developed, such as those targeting the $\mathrm{recA}$ and $\mathrm{fliC}$ genes in Dickeya (Parkinson et al. 2009; Van Vaerenbergh et al. 2012).

This work proposes a PCR-sequencing barcode method for the identification, in a single assay, of all Dickeya and Pectobacterium pectinolytic species or subspecies causing blackleg and soft rot diseases on a potato plant host. The most recent description of the Dickeya and Pectobacterium genera and classification (Zhang et al. 2016) was retained to develop this "all-in-one" molecular tool that exploits the housekeeping gene gapA (coding for the glyceraldehyde-3phosphate dehydrogenase A) as a molecular barcode.

\section{Materials and Methods}

Genome resource and gapA gene alignment. All 53 Dickeya and Pectobacterium genomes were retrieved from the National Center for Biotechnology Information (NCBI). These genomes are representative of the known diversity of the two genera (Zhang et al. 2016). Genome accession numbers and additional characteristics are provided in Table 1. The gapA genes were retrieved from genomes and aligned using CLC Genomics Workbench 9.0.1 (https://www. qiagenbioinformatics.com). Taxon-specific nucleotides were defined as those distinctive as compared with the other taxons. Phylogeny reconstruction was performed with the neighbor-joining statistical method (Tamura et al. 2004) using MEGA7 (Kumar et al. 2016).

Isolation of Dickeya and Pectobacterium strains from potato field. Plants with blackleg symptoms were collected from 10 French potato fields. Symptomatic tissues were cut into 3- to 5$\mathrm{mm}$ piecesa nd incubated during $1 \mathrm{~h}$ at room temperature in a sterile solution buffer $\left(\mathrm{Na}_{2} \mathrm{HPO}_{4}, 12 \mathrm{H}_{2} \mathrm{O} 1.07 \%, \mathrm{KH}_{2} \mathrm{PO}_{4} 0.27 \%\right.$, $\left.\mathrm{pH} 7.0\right)$. Bacterial suspensions were diluted and plated $48 \mathrm{~h}$ at $28^{\circ} \mathrm{C}$ on CVP 
Table 1. Dickeya and Pectobacterium genomes used in this study

\begin{tabular}{|c|c|c|c|}
\hline Species, strain & Isolation source & $\begin{array}{l}\text { Geographical origin, } \\
\text { year of isolation }\end{array}$ & GenBank Accession number \\
\hline \multicolumn{4}{|l|}{ Dickeya dadantii } \\
\hline NCPPB $898^{\mathrm{T}}$ & Pelargonium capitatum & Comoros, 1960 & CM001976.1 \\
\hline 3937 & Saintpaulia ionantha & France, 1977 & CP002038.1 \\
\hline NCPPB 3537 & Solanum tuberosum & Peru & CM001982.1 \\
\hline \multicolumn{4}{|l|}{ Dickeya dianthicola } \\
\hline NCPPB $453^{\mathrm{T}}$ & Dianthus caryophyllus & UK, 1956 & CM001841.1 \\
\hline IPO 980 & Solanum tuberosum & Netherlands & CM002023.1 \\
\hline RNS04.9 & Solanum tuberosum & France, 2004 & APVF00000000.1 \\
\hline GBBC 2039 & Solanum tuberosum & Belgium & СM001838.1 \\
\hline NCPPB 3534 & Solanum tuberosum & Netherlands & CM001840.1 \\
\hline \multicolumn{4}{|l|}{ Dickeya paradisiaca } \\
\hline NCPPB $2511^{\mathrm{T}}$ & Musa paradisiaca & Colombia, 1970 & CM001857.1 \\
\hline \multicolumn{4}{|l|}{ Dickeya solani } \\
\hline IPO $2222^{\mathrm{T}}$ & Solanum tuberosum & Netherlands, 2007 & СM001859.1 \\
\hline $05.1 .2 \mathrm{~A}$ & Solanum tuberosum & France, 2005 & JWMJ00000000.1 \\
\hline MK10 & Solanum tuberosum & Israel & CM001839.1 \\
\hline MK16 & River water & UK & CM001842.1 \\
\hline GBBC 2040 & Solanum tuberosum & Belgium & CM001860.1 \\
\hline RNS08.23.3.1.A & Solanum tuberosum & France, 2008 & AMYI00000000.1 \\
\hline 07.7.3B & Solanum tuberosum & France, 2007 & JWLR00000000.1 \\
\hline \multicolumn{4}{|c|}{ Pectobacterium carotovorum subsp. actinidiae } \\
\hline KKH3 ${ }^{\mathrm{T}}$ & Actinidia chinensis & South Korea, 2006 & JRMH00000000.1 \\
\hline \multicolumn{4}{|c|}{ Pectobacterium carotovorum subsp. brasiliense } \\
\hline LMG $21371^{\mathrm{T}}$ & Solanum tuberosum & Brazil, 1999 & JQOE00000000.1 \\
\hline LMG 21372 & Solanum tuberosum & Brazil, 1999 & JQOD00000000.1 \\
\hline CFIA1009 & Solanum tuberosum & Canada, 2008 & JPSN00000000.1 \\
\hline CFIA1033 & Solanum tuberosum & Canada, 2009 & JPSO00000000.1 \\
\hline YC D49 & Brassica rapa subsp. chinensis & China, 2013 & JUJB00000000.1 \\
\hline YC D62 & Brassica rapa subsp. chinensis & China, 2013 & JUJD00000000.1 \\
\hline YC D64 & Brassica rapa subsp. chinensis & China, 2013 & JUJE00000000.1 \\
\hline YC D21 & Brassica rapa subsp. chinensis & China, 2013 & JUJJ00000000.1 \\
\hline YC D29 & Brassica rapa subsp. chinensis & China, 2013 & JUJK00000000.1 \\
\hline YC T31 & Brassica rapa subsp. chinensis & China, 2013 & JUJL00000000.1 \\
\hline YC D65 & Brassica rapa subsp. chinensis & China, 2013 & JUJN00000000.1 \\
\hline YC D52 & Brassica rapa subsp. chinensis & China, 2013 & JUJC00000000.1 \\
\hline \multicolumn{4}{|c|}{$\begin{array}{l}\text { Pectobacterium carotovorum subsp. } \\
\text { carotovorum }\end{array}$} \\
\hline ICMP $5702^{\mathrm{T}}$ & Solanum tuberosum & Denmark, 1952 & AODT00000000.1 \\
\hline WPP14 & Solanum tuberosum & USA, 2001 & ABVY00000000.1 \\
\hline NCPPB 3395 & Solanum tuberosum & Netherlands, 1985 & JQHN00000000.1 \\
\hline YC D57 & Brassica rapa subsp. chinensis & China, 2013 & JUJG00000000.1 \\
\hline YC T1 & Brassica rapa subsp. chinensis & China, 2013 & JUJI00000000.1 \\
\hline YC D16 & Brassica rapa subsp. chinensis & China, 2013 & JUJO00000000.1 \\
\hline YC T39 & Brassica rapa subsp. chinensis & China, 2013 & JUJQ00000000.1 \\
\hline $\mathrm{BC}$ T2 & Brassica rapa subsp. pekinensis & China, 2013 & JUJR00000000.1 \\
\hline $\mathrm{BC}$ T5 & Brassica rapa subsp. pekinensis & China, 2013 & JUJS00000000.1 \\
\hline \multicolumn{4}{|c|}{ Pectobacterium aroidearum } \\
\hline PC1 & Ornithogalum dubium & Israel, 2004 & СР001657.1 \\
\hline \multicolumn{4}{|c|}{ Pectobacterium carotovorum subsp. odoriferum } \\
\hline NCPPB $3839^{\mathrm{T}}$ & Cichorium intybus & France, 1978 & JQOG00000000.1 \\
\hline NCPPB 3841 & Cichorium intybus & France, 1979 & JQOF00000000.1 \\
\hline BC S7 & Brassica rapa subsp. pekinensis & China, 2007 & СР009678.1 \\
\hline \multicolumn{4}{|c|}{ Pectobacterium atrosepticum } \\
\hline ICMP $1526^{\mathrm{T}}$ & Solanum tuberosum & UK, 1957 & ALIV00000000.1 \\
\hline SCRI1043 & Solanum tuberosum & $\mathrm{UK}, 1985$ & BX950851.1 \\
\hline JG10-08 & Solanum tuberosum & China, 2010 & СР007744.1 \\
\hline $21 \mathrm{~A}$ & Solanum tuberosum & Belarus, 1978 & СР009125.1, СР009126.1 \\
\hline CFBP 6276 & Solanum tuberosum & France, 1999 & ASAB00000000.1 \\
\hline \multicolumn{4}{|c|}{ Pectobacterium parmentieri } \\
\hline RNS08.42.1. $\mathrm{A}^{\mathrm{T}}$ & Solanum tuberosum & France, 2008 & СР015749.1 \\
\hline WPP163 & Solanum tuberosum & USA, 2004 & СР001790.1 \\
\hline SCC3193 & Solanum tuberosum & Finland, 1980s & СР003415.1 \\
\hline CFIA1002 & Solanum tuberosum & Canada, 2007 & JENG00000000.1 \\
\hline \multicolumn{4}{|c|}{ Pectobacterium wasabiae } \\
\hline CFBP $3304^{\mathrm{T}}$ & Eutrema wasabi & Japan, 1985 & СР015750.1 \\
\hline NCPPB3702 & Eutrema wasabi & Japan, 1985 & JQOH00000000.1 \\
\hline
\end{tabular}


medium (Hélias et al. 2012). Single colonies on CVP medium were purified on TY medium (tryptone $5 \mathrm{~g} /$ liter, yeast extract $3 \mathrm{~g} / \mathrm{liter}$, and agar $1.5 \%$ ) and then incubated $48 \mathrm{~h}$ at $28^{\circ} \mathrm{C}$. Before gapA sequencing, all the isolates were characterized using the taxon-specific PCR

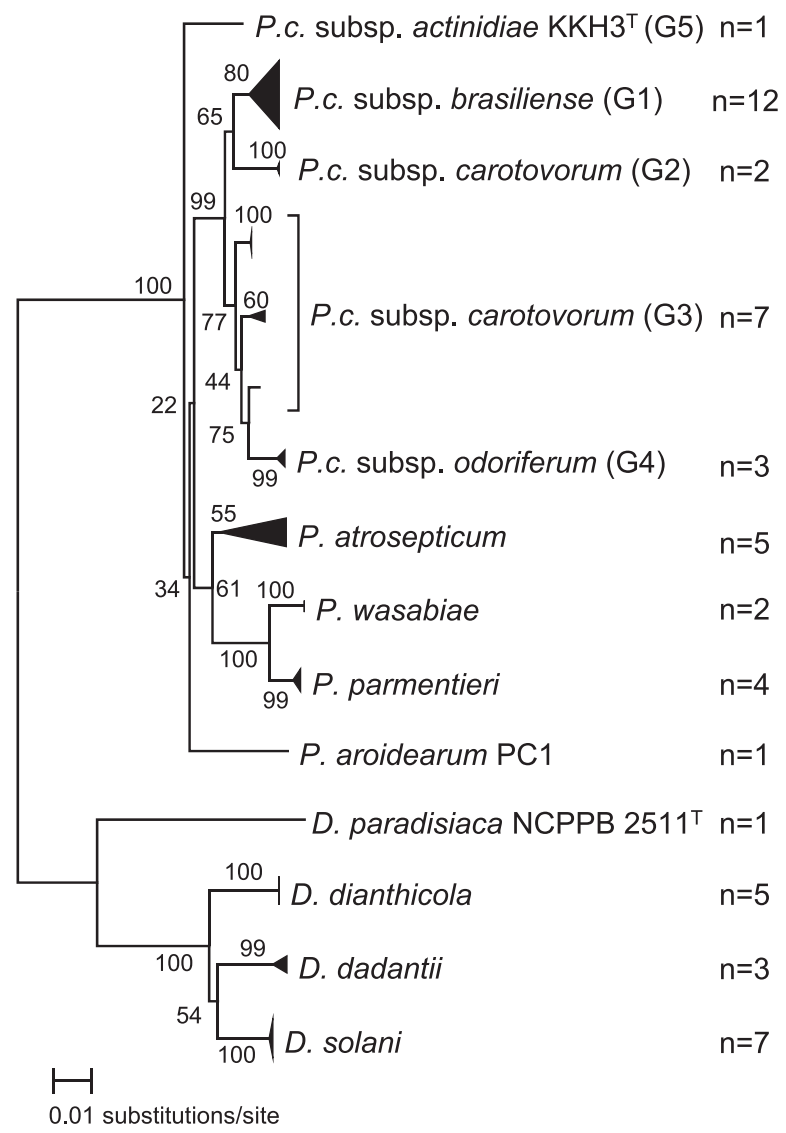

Fig. 1. The gapA phylogeny in Dickeya and Pectobacterium. The gapA genes were recovered from 53 genomes, aligned, and used for building a phylogenetic tree with the neighbor-joining statistical method using MEGA7. One thousand bootstrap replicates were computed. The subtree was compressed and grouped by species or subspecies. The number of genomes used is indicated next to each taxon. methods (Darrasse et al. 1994; Duarte et al. 2004; Frechon et al. 1998; Kang et al. 2003; Kim et al. 2012; Nassar et al. 1996).

gapA-primers and PCR conditions. The gapA primers gapA-7-F 5'-ATCAAAGTAGGTATCAACGG and gapA-938-R 5'-TC RTACCARGAAACCAGTT were designed using Primer3 (Untergasser et al. 2012). The size of the amplicon is $932 \mathrm{bp}$ in length. Primers were synthesized by Eurofins Genomics (Ebersberg, Germany).

The gapA-PCR assay was performed directly on liquid bacterial cultures. One single colony of each strain was cultured in $5 \mathrm{ml}$ liquid TY medium (tryptone $5 \mathrm{~g} /$ liter, yeast extract $3 \mathrm{~g} /$ liter) overnight. Two microliters of the culture were diluted with $18 \mu \mathrm{l}$ of TE buffer, heated $10 \mathrm{~min}$ at $99^{\circ} \mathrm{C}$, and immediately frozen at $-20^{\circ} \mathrm{C}$. PCR assays were performed in $25 \mu \mathrm{l}$ reaction mixture (final volume) containing $0.1 \mu \mathrm{l}$ of EurobioTaq $(5 \mathrm{u} / \mu \mathrm{l}) ; 2.5 \mu \mathrm{l}$ of $10 \times$ buffer; $2 \mu \mathrm{l}$ of $\mathrm{MgCl}_{2} 25 \mathrm{mM}$; $2.5 \mu \mathrm{l}$ of Eurobio mix dNTP $1 \mathrm{mM} ; 1 \mu \mathrm{l}$ of each primer $1 \mu \mathrm{M}$; $13.9 \mu \mathrm{l}$ of sterile Milli-Q $\mathrm{H}_{2} \mathrm{O}$; and $2 \mu \mathrm{l}$ of lysed culture in TE buffer. PCRs were carried out with a 2720 Thermal Cycler (Applied Biosystems, Foster City, CA). Cycling parameters were $94^{\circ} \mathrm{C}$ for $5 \mathrm{~min}, 40$ cycles of $94^{\circ} \mathrm{C}$ for $30 \mathrm{~s}, 54^{\circ} \mathrm{C}$ for $30 \mathrm{~s}$, and $72^{\circ} \mathrm{C}$ for $30 \mathrm{~s}$, with a final extension at $72^{\circ} \mathrm{C}$ for $5 \mathrm{~min}$. PCR products were separated in $2 \%$ agarose gels in TBE buffer, at $150 \mathrm{~V}$ for $30 \mathrm{~min}$ and bands were revealed with ethidium bromide staining.

Sequencing and analyses of PCR products. PCR products were sequenced using Sanger technology by the GATC NightXpress service (GATC Biotech AG, Cologne, Germany). After alignment and trimming of all PCR products, 812 bp of gapA sequences were analyzed for the presence of signature-nucleotides and a phylogeny was established, all as described above.

\section{Results}

The gapA phylogeny in Dickeya and Pectobacterium. A phylogeny of 53 gapA genes was constructed with neighbor-joining statistical method. Subtrees were compressed and grouped by species or subspecies (Fig. 1). In the case of $P$. carotovorum subspecies, the classification G1 to G5 was added in reference to the data from Zhang et al. 2016. The gapA phylogeny permitted a clear separation of the investigated species and subspecies, supporting the proposition of this gene as an appropriate genetic marker. Noticeably, the new species $P$. parmentieri (Khayi et al. 2016) was clearly separated from $P$. wasabiae species. Furthermore, strain PC1, which was isolated in Israel from Star of Bethlehem plants (Ornithogalum dubium; Luzzatto et al. 2007) and previously identified as a Pcc, was

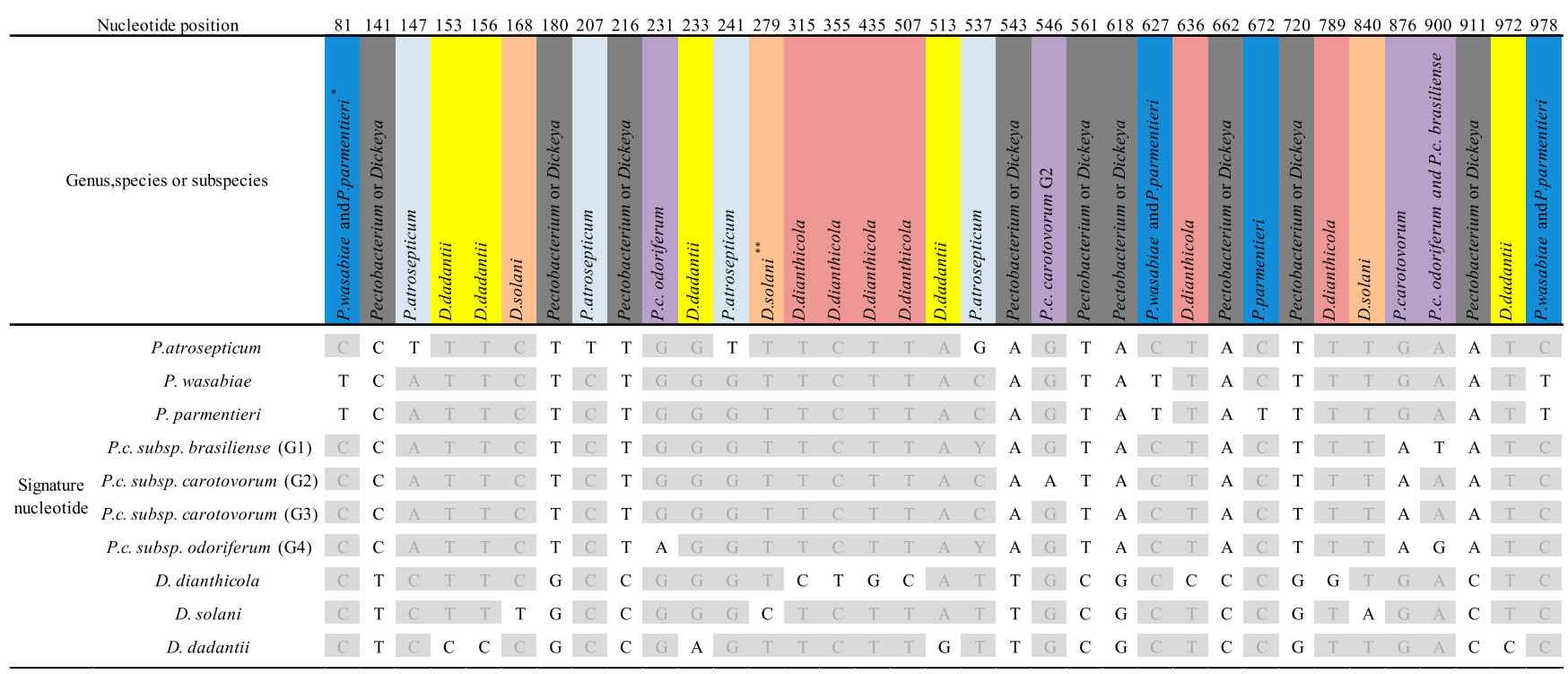

Fig. 2. The gapA signature nucleotides. This figure shows signature nucleotides of the Dickeya and Pectobacterium species and subspecies. Genera signature nucleotides are represented in dark gray, $P$. atrosepticum signature nucleotides are colored in light gray, $P$. parmentieri and $P$. wasabiae in dark blue, Pectobacterium carotovorum in purple, $D$. dadantii in yellow, $D$. dianthicola for light red, and $D$. solani in salmon pink. Nucleotide numbering starts at the first nucleotide of the codon ATG. Asterisks indicate uncommon variations: ${ }^{*}=$ T at position 81 in the strain Pcb YC D65; ${ }^{*}=\mathrm{C}$ at position 279 in the strain Pcc YC T1. Y represents $\mathrm{C}$ or T nucleotide. 


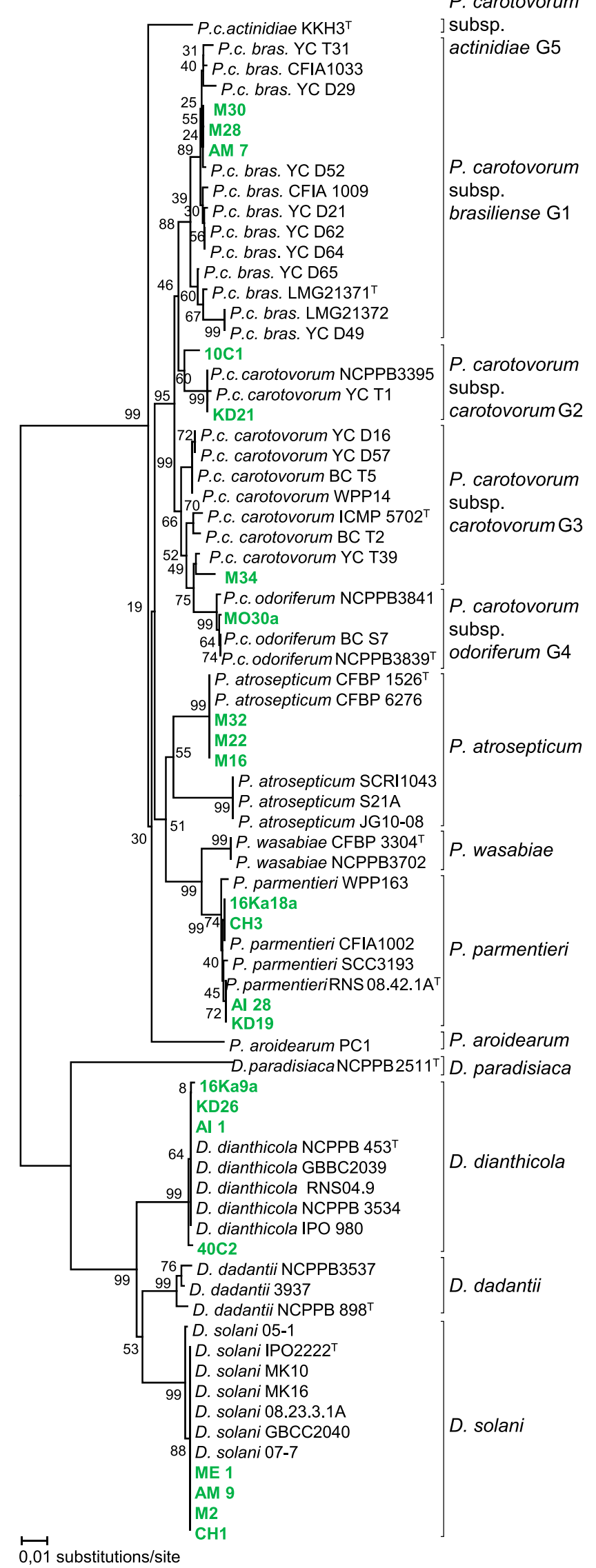

Fig. 3. The gapA phylogeny for taxonomic assignation of field isolates. The gapA phylogeny combines 22 isolates from potato symptomatic tissues (green) listed in Table 2 and 53 genomes of Pectobacterium and Dickeya (black) listed in Table 1. Tree was performed with the neighbor-joining statistical method using MEGA7. One thousand bootstrap replicates were computed. recently reclassified in $P$. aroidearum (Nabhan et al. 2013). This strain clearly emerged in a separated branch that was distant from the Pcc clade.

Identification of signature-nucleotides. The gapA alignment also revealed 35 signature nucleotides that distinguished the Pectobacterium and Dickeya taxa (Fig. 2). Nine nucleotides distinguished the genera Pectobacterium and Dickeya. In addition to these genus signature nucleotides, additional positions discriminated the different species: three nucleotides were specific for $D$. solani, five for $D$. dadantii, six for $D$. dianthicola, four for P. atrosepticum, one for Pectobacterium carotovorum, three for the sister species $P$. wasabiae and $P$. parmentieri, and one for distinguishing $P$. parmentieri from $P$. wasabiae. At the subspecies level, three additional nucleotides separated Pcc, Pco, and Pcb, as well as G2 and G3 phyla.

Identification of pectinolytic strains isolated from blackleg symptoms in potato fields. Twenty-two strains isolated on blackleg symptoms from 10 French potato fields have been collected since 2013. Isolates were assigned to Dickeya and Pectobacterium taxa using the already available PCR methods (Darrasse et al. 1994; Duarte et al. 2004; Frechon et al. 1998; Kang et al. 2003; Kim et al. 2012; Nassar et al. 1996). Then, after PCR with gapA primers and amplicon sequencing, gapA sequences were trimmed and aligned and a phylogeny tree was constructed (Fig. 3). All the pectinolytic strains isolated from potato fields branched with known Dickeya and Pectobacterium clades. In addition, the signature nucleotides were examined. For each of the 22 field strains, the signature nucleotides allowed unambiguous assignation to a species, or subspecies in the case of $P$. carotovorum (Table 2). The taxonomic assignations performed with the gapA phylogeny and the gapA signature-nucleotide analysis were congruent. Using the gapA PCR-sequencing tool, three Pcb, three Pcc, one Pco, three $P$. atrosepticum, four $P$. parmentieri, four $D$. dianthicola, and four $D$. solani were identified.

\section{Discussion}

We reported here a simple (a single PCR primer pair for amplifying Dickeya and Pectobacterium gapA barcodes) and rapid (one day for external Sanger sequencing) methodology for identifying species and subspecies of pectinolytic potato pathogens belonging to the Dickeya and Pectobacterium genera. PCR assays were performed on a bacterial cell suspension without DNA extraction. Previous work has already considered partial sequence of the gapA gene in

Table 2. Pectinolytic strains isolated from potato fields

\begin{tabular}{llclc}
\hline Isolate & Field & $\begin{array}{c}\text { Year of } \\
\text { isolation }\end{array}$ & $\begin{array}{c}\text { gapA } \\
\text { identification }\end{array}$ & $\begin{array}{c}\text { GenBank } \\
\text { gapA } \\
\text { sequence }\end{array}$ \\
\hline 10C1 & Field A & 2013 & Pcc & KY047578 \\
40C2 & Field B & 2013 & D. dianthicola & KY047579 \\
MO30a & Field C & 2014 & Pco & KY047580 \\
16Ka9 & Field D & 2016 & D. dianthicola & KY047581 \\
16Ka18a & Field D & 2016 & P. parmentieri & KY047582 \\
ME1 & Field E & 2016 & D. solani & KY047583 \\
AI1 & Field F & 2016 & D. dianthicola & KY047584 \\
AI28 & Field F & 2016 & P. parmentieri & KY047585 \\
AM7 & Field G & 2016 & Pcb & KY047586 \\
AM9 & Field G & 2016 & D. solani & KY047587 \\
M2 & Field H & 2016 & D. solani & KY047588 \\
M16 & Field H & 2016 & P. atrosepticum & KY047589 \\
M22 & Field H & 2016 & P. atrosepticum & KY047590 \\
M28 & Field H & 2016 & Pcb & KY047591 \\
M30 & Field H & 2016 & Pcb & KY047592 \\
M32 & Field H & 2016 & P. atrosepticum & KY047593 \\
M34 & Field H & 2016 & Pcc & KY047594 \\
KD19 & Field I & 2016 & P. parmentieri & KY047595 \\
KD21 & Field I & 2016 & Pcc & KY047596 \\
KD26 & Field I & 2016 & D. dianthicola & KY047597 \\
CH1 & Field J & 2016 & D. solani & KY047598 \\
CH3 & Field J & 2016 & P. parmentieri & KY047599 \\
\hline & & & &
\end{tabular}


MLSA (Ma et al. 2007; Nabhan et al. 2012). In this study, special attention was paid to the selection of primers in order to generate large-sized gapA amplicons, and hence to maximize the associated taxonomic information. The gapA phylogeny was congruent with the topology of the phylogeny based on the concatenation of $895 \mathrm{nu}-$ cleotide sequences (Zhang et al. 2016.). Noticeably, in silico analysis showed that these gapA primers potentially amplify the gapA gene in some other enterobacteria, so the gapA PCR-product needs to be sequenced for taxonomical assignation. This is expected for a DNAbarcode.

For an accurate taxonomic assignation, we recommended performing an alignment of the tested gapA sequence with gapA genes belonging to the different species and subspecies listed in Table 1. Then, this alignment may be used to construct a phylogenetic tree (e.g., Fig. 3) and to identify the signature nucleotides described in the Figure 2. These two complementary analyses reinforced the taxonomic assignation based on gapA sequencing. Unlike speciesspecific, PCR identification methods based on the presence or absence of an amplicon, the gapA method authorizes the archiving of sequences that can be stored and reused for further analyses. Another value of the gapA tool lies in its adaptability to the evolution of Dickeya and Pectobacterium taxonomy. As an example, the phyla G2 and G3 that are potential $P$. carotovorum subspecies may be distinguished using gapA sequences.

By testing the gapA tool on 22 pectinolytic strains isolated from potato fields, several expected taxa (Pcb, Pcc, P. atrosepticum, $P$. parmentieri, $D$. dianthicola, and $D$. solani) were identified, including Pco. To our knowledge, this is the first published report of such an identification of this subspecies on a potato host. Pco were recurrently isolated from chicory or others plants. Waleron et al. 2014 showed that Pco strains isolated from chicory could induce severe maceration symptoms when inoculated directly on potato tuber. Our work suggests that pathogen transmission may occur between plants cultivated in the same area.

Another potential interest of the gapA tool involves investigations on the natural diversity of pectinolytic Dickeya and Pectobacterium collected from different host and nonhost plants, and soil and surface water samples. A broader knowledge of this diversity will help understanding the genetic resource and reservoirs of potential forthcoming disease outbreaks.

\section{Literature Cited}

Barras, F., van Gijsegem, F., and Chatterjee, A. K. 1994. Extracellular enzymes and pathogenesis of soft-rot Erwinia. Annu. Rev. Phytopathol. 32:201-234.

Czajkowski, R., Pérombelon, M. C. M., van Veen, J. A., and van der Wolf, J. M. 2011. Control of blackleg and tuber soft rot of potato caused by Pectobacterium and Dickeya species, a review: Control of Dickeya and Pectobacterium species in potato. Plant Pathol. 60:999-1013.

Darrasse, A., Priou, S., Kotoujansky, A., and Bertheau, Y. 1994. PCR and restriction fragment length polymorphism of a pel gene as a tool to identify Erwinia carotovora in relation to potato diseases. Appl. Environ. Microbiol. 60:1437-1443

de Werra, P., Bussereau, F., Keiser, A., and Ziegler, D. 2015. First report of potato blackleg caused by Pectobacterium carotovorum subsp. brasiliense in Switzerland. Plant Dis. 99:551

Duarte, V., De Boer, S. H., Ward, L. J., and Oliveira, A. M. R. 2004. Characterization of atypical Erwinia carotovora strains causing blackleg of potato in Brazil. J. Appl. Microbiol. 96:535-545.

Frechon, D., Exbrayat, P., Hélias, V., Hyman, L. J., Jouan, B., Llop, P., et al. 1998. Evaluation of a PCR kit for the detection of Erwinia carotovora subsp. atroseptica on potato tubers. Potato Res. 41:163-173.

Gardan, L., Gouy, C., Christen, R., and Samson, R. 2003. Elevation of three subspecies of Pectobacterium carotovorum to species level: Pectobacterium atrosepticum sp. nov., Pectobacterium betavasculorum sp. nov. and Pectobacterium wasabiae sp. nov. Int. J. Syst. Evol. Microbiol. 53:381-391.

Hélias, V., Hamon, P., Huchet, E., Wolf, J. V. D., and Andrivon, D. 2012. Two new effective semiselective crystal violet pectate media for isolation of Pectobacterium and Dickeya: Isolating pectolytic bacteria on CVP. Plant Pathol. 61:339-345.

Hélias, V., Le Roux, A.-C., Bertheau, Y., Andrivon, D., Gauthier, J.-P., and Jouan, B. 1998. Characterisation of Erwinia carotovora subspecies and detection of
Erwinia carotovora subsp. atroseptica in potato plants, soil and water extracts with PCR-based methods. Eur. J. Plant Pathol. 104:685-699.

Kang, H. W., Kwon, S. W., and Go, S. J. 2003. PCR-based specific and sensitive detection of Pectobacterium carotovorum ssp. carotovorum by primers generated from a URP-PCR fingerprinting-derived polymorphic band. Plant Pathol. 52:127-133.

Khayi, S., Cigna, J., Chong, T. M., Quêtu-Laurent, A., Chan, K. G., Hélias, V., and Faure, D. 2016. Transfer of the potato plant isolates of Pectobacterium wasabiae to Pectobacterium parmentieri sp. nov. Int. J. Syst. Evol. Microbiol. 66: 5379-5383.

Kim, M. H., Cho, M. S., Kim, B. K., Choi, H. J., Hahn, J. H., Kim, C. K., Kang, M. J., Kim, S. H., and Park, D. S. 2012. Quantitative real-time polymerase chain reaction assay for detection of Pectobacterium wasabiae using YD repeat protein gene-based primers. Plant Dis. 96:253-257.

Kumar, S., Stecher, G., and Tamura, K. 2016. MEGA7: Molecular Evolutionary Genetics Analysis version 7.0 for bigger datasets. Mol. Biol. Evol. 33 $1870-1874$.

Laurila, J., Hannukkala, A., Nykyri, J., Pasanen, M., Hélias, V., Garlant, L., and Pirhonen, M. 2010. Symptoms and yield reduction caused by Dickeya spp. strains isolated from potato and river water in Finland. Eur. J. Plant Pathol. 126:249-262.

Luzzatto, T., Yishay, M., Lipsky, A., Ion, A., Belausov, E., and Yedidia, I. 2007. Efficient, long-lasting resistance against the soft rot bacterium Pectobacterium carotovorum in calla lily provided by the plant activator methyl jasmonate. Plant Pathol. 56:692-701.

Ma, B., Hibbing, M. E., Kim, H.-S., Reedy, R. M., Yedidia, I., Breuer, J., Glasner J. D., Perna, N. T., Kelman, A., and Charkowski, A. O. 2007. Host range and molecular phylogenies of the soft rot enterobacterial genera Pectobacterium and Dickeya. Phytopathology 97:1150-1163.

Nabhan, S., De Boer, S. H., Maiss, E., and Wydra, K. 2013. Pectobacterium aroidearum sp. nov., a soft rot pathogen with preference for monocotyledonous plants. Int. J. Syst. Evol. Microbiol. 63:2520-2525.

Nabhan, S., Wydra, K., Linde, M., and Debener, T. 2012. The use of two complementary DNA assays, AFLP and MLSA, for epidemic and phylogenetic studies of pectolytic enterobacterial strains with focus on the heterogeneous species Pectobacterium carotovorum: Phylogenetic focus on soft-rot plant pathogens. Plant Pathol. 61:498-508.

Nassar, A., Darrasse, A., Lemattre, M., Kotoujansky, A., Dervin, C., Vedel, R. Bertheau, Y. 1996. Characterization of Erwinia chrysanthemi by pectinolytic isozyme polymorphism and restriction fragment length polymorphism analysis of PCR-amplified fragments of pel genes. Appl. Environ. Microbiol. 62:2228-2235

Parkinson, N., Stead, D., Bew, J., Heeney, J., Tsror (Lahkim), L., and Elphinstone, J. 2009. Dickeya species relatedness and clade structure determined by comparison of recA sequences. Int. J. Syst. Evol. Microbiol. 59:2388-2393.

Pérombelon, M. C. M. 2002. Potato diseases caused by soft rot erwinias: An overview of pathogenesis. Plant Pathol. 51:1-12.

Potrykus, M., Sledz, W., Golanowska, M., Slawiak, M., Binek, A., Motyka, A., Zoledowska, S., Czajkowski, R., and Lojkowska, E. 2014. Simultaneous detection of major blackleg and soft rot bacterial pathogens in potato by multiplex polymerase chain reaction. Ann. Appl. Biol. 165:474-487.

Samson, R., Legendre, J. B., Christen, R., Fischer-Le Saux, M., Achouak, W., and Gardan, L. 2005. Transfer of Pectobacterium chrysanthemi (Burkholder et al. 1953) Brenner et al. 1973 and Brenneria paradisiaca to the genus Dickeya gen. nov. as Dickeya chrysanthemi comb. nov. and Dickeya paradisiaca comb. nov. and delineation of four novel species, Dickeya dadantii sp. nov., Dickeya dianthicola sp. nov., Dickeya dieffenbachiae sp. nov. and Dickeya zeae sp. nov. Int. J. Syst. Evol. Microbiol. 55:1415-1427.

Tamura, K., Nei, M., and Kumar, S. 2004. Prospects for inferring very large phylogenies by using the neighbor-joining method. Proc. Natl. Acad. Sci. 101:11030-11035.

Toth, I. K., van der Wolf, J. M., Saddler, G., Lojkowska, E., Hélias, V., Pirhonen, M., et al. 2011. Dickeya species: An emerging problem for potato production in Europe: Dickeya spp. on potato in Europe. Plant Pathol. 60:385-399.

Untergasser, A., Cutcutache, I., Koressaar, T., Ye, J., Faircloth, B. C., Remm, M., et al. 2012. Primer3-new capabilities and interfaces. Nucleic Acids Res. 40: e115.

Van Vaerenbergh, J., Baeyen, S., De Vos, P., and Maes, M. 2012. Sequence Diversity in the Dickeya fliC gene: Phylogeny of the Dickeya genus and TaqMan PCR for "D. solani," new biovar 3 variant on potato in Europe. PLoS One 7:e35738.

Waldee, E. L. 1942. Comparative studies of some peritrichous phytopathogenic bacteria. PhD. thesis. Iowa State College, Ames, IA

Waleron, M., Waleron, K., and Lojkowska, E. 2014. Characterization of Pectobacterium carotovorum subsp. odoriferum causing soft rot of stored vegetables. Eur. J. Plant Pathol. 139:457-469.

Zhang, Y., Fan, Q., and Loria, R. 2016. A re-evaluation of the taxonomy of phytopathogenic genera Dickeya and Pectobacterium using whole-genome sequencing data. Syst. Appl. Microbiol. 39:252-259. 